\title{
COMPOSTOS NÃO VOLÁTEIS EM CAFÉS DA REGIÃO SUL DE MINAS SUBMETIDOS A DIFERENTES PONTOS DE TORRAÇÃO
}

\author{
Non-volatile compounds in coffee from the south of Minas Gerais state region \\ submitted to different roasting degrees
}

\author{
Mirian Pereira Rodarte ${ }^{1}$, Sheila Andrade Abrahão², \\ Rosemary Gualberto Fonseca Alvarenga Pereira ${ }^{3}$, Marcelo Ribeiro Malta ${ }^{4}$
}

\begin{abstract}
RESUMO
O processo de torração do café induz alterações físicas, químicas e sensoriais na matéria-prima, cuja intensidade e tipo dependem, principalmente, da composição química dos grãos e do tempo e temperatura utilizados na execução do mesmo. Este processo promove a degradação, formação e volatilização de vários compostos. Comercialmente, existem cafés torrados e moídos em diferentes pontos de torração, os quais originam bebidas com diferentes propriedades sensoriais e nutricionais. Os compostos trigonelina, ácidos clorogênicos e cafeína interferem no sabor e aroma do café. A trigonelina e os ácidos clorogênicos vêm sendo estudados também quanto ao aspecto nutricional, uma vez que esses compostos possuem ação benéfica à saúde. Esses compostos são solúveis em água quente, portanto, estarão presentes na bebida em função da sua estabilidade no processo de torração. Conduziu-se este trabalho, com o objetivo de avaliar as concentrações dos compostos trigonelina, ácidos clorogênicos e cafeína em cafés da espécie Coffea arabica L. classificados como bebida mole, dura e rio submetidos a três pontos de torração: claro, médio e escuro. As torrações mais acentuadas promoveram uma maior degradação de trigonelina e ácido 5-cafeoilquínico, enquanto que a torração clara promoveu degradação apenas para o ácido clorogênico, não interferindo nas concentrações de trigonelina. A degradação da cafeína não ocorreu em nenhum ponto de torração.
\end{abstract}

Termos para indexação: CLAE, torração, trigonelina, ácidos clorogênicos, cafeína.

\begin{abstract}
The roasting process of coffee induces sensorial, chemical and physical alterations in the raw material. The type and intensity of the process depend mainly on the chemical composition of the grains and on the time and temperature used. This process promotes the degradation, formation and volatilisation of several compounds. There are roast and ground coffees submitted to different roasting conditions available in the market, which give origin to beverages with different sensorial and nutritional properties. The compounds trigonelline, chlorogenic acids and caffeine interfere with the flavor of the coffee. The trigonelline and the chlorogenic acids were studied considering their nutritional aspect as well, since these compounds and"or their degradation products have a beneficial action to our health. These compounds are soluble in hot water therefore they will be present in the beverage depending on their stability through the roasting process. The aim of this work was to asses the concentrations of trigonelline, chlorogenic acids and caffeine in coffees of the species Coffea arabica, classified as soft, hard, and rio which were submitted to three roasting degrees: light, medium, and dark. The most intense roasting process generated a greater degradation of trigonelline and 5-caffeoilquinic (5-CQA) while the light roasting caused degradation just of the chlorogenic acid, not interfering with the trigonelline concentrations. Caffeine was not degraded at any roasting degree.
\end{abstract}

Index terms: HPLC, roasting, trigonelline, chlorogenic acids, caffeine.

(Recebido em 23 de outubro de 2007 e aprovado em 22 de julho de 2008)

\section{INTRODUÇÃO}

As diferenças na composição química e características dos grãos de café beneficiado, contribuem para que os mesmos, quando submetidos ao processo de torração forneçam bebidas com características sensoriais diferenciadas (BORÉM et al., 2008). As diversas reações pirolíticas que ocorrem durante a torração resultam na degradação, formação e volatilização de vários compostos químicos. Este processo é considerado como a principal etapa da industrialização, pois é durante o mesmo que

\footnotetext{
Farmacêutica-Bioquímica, Doutora em Ciência dos Alimentos - Departamento Ciência dos Alimentos/DCA - Universidade Federal de Lavras/UFLA Cx. P. 3037 - 37200-000 - Lavras, MG - mpr@vialavras.com.br

${ }^{2}$ Nutricionista, Doutoranda em Ciência dos Alimentos - Departamento Ciência dos Alimentos/DCA - Universidade Federal de Lavras/UFLA - Cx. P. 3037 37200-000 - Lavras, MG - sheila_nutri@hotmail.com

${ }^{3}$ Farmacêutica, Doutora, Professora - Departamento Ciência dos Alimentos/DCA - Universidade Federal de Lavras/UFLA - Cx. P. 3037 - $37200-000$ Lavras, MG - rosegfap@ufla.br

${ }^{4}$ Engenheiro Agrônomo, Doutor em Ciência dos Alimentos - Empresa de Pesquisa Agropecuária de Minas Gerais/EPAMIG - Cx. P. 176 - $37200-000$ Lavras, MG - marcelomalta@epamig.br
} 
sabor e aroma são desenvolvidos e além disso, dependendo do tipo de torração utilizada, podem ocorrer mudanças desejáveis ou não nos grãos, tais como a perda ou preservação de constituintes nutricionalmente importantes.

Os diferentes setores ligados à comercialização do produto adotam diferentes procedimentos de torração, os quais diferem entre si, de acordo com a finalidade a que se destinam. Assim, a torração clara ou americana, é mais utilizada para a classificação da bebida para a comercialização do produto beneficiado. Este tipo de torração é empregado por facilitar a percepção de atributos sensoriais desejáveis ou não. A torração média é indicada para a produção de cafés expressos e preparação de bebidas com a utilização de filtros, pois ressalta o sabor e aroma característicos do café. A torração escura diminui a acidez, acentua o sabor amargo, reduz a doçura e origina bebidas mais escuras, sendo tradicionalmente ainda utilizada por várias indústrias com finalidades diferentes, ou seja, tanto para atender a segmentos de consumo que interpretam a coloração mais intensa como um produto que fornece maior rendimento, como para camuflar sabores e aromas indesejáveis originados pelo uso de cafés de qualidade inferior (PEREIRA, 2003). Dentre os diferentes componentes químicos que podem ser alterados ou perdidos durante a torração, atenção especial tem sido direcionada para a trigonelina, cafeína e principalmente, para os ácidos clorogênicos.

A trigonelina e os ácidos clorogênicos apresentam importância biológica, uma vez que a trigonelina é precursora da niacina, que é formada no processo de torração e atua como fator preventivo da pelagra e faz parte das coenzimas desidrogenase I e desidrogenase II, importantes em várias reações enzimáticas de oxidação (BOBBIO \& BOBBIO, 2003). Os ácidos clorogênicos apresentam propriedades antioxidantes e produzem derivados com diferentes atividades biológicas tais como as lactonas de ácidos clorogênicos que apresentam afinidade de ligação em centros opióides do cérebro e os isômeros do grupo de ácidos dicafeoilquínicos, que apresentam in vitro atividade inibitória de integrases na replicação do vírus HIV (BOUBLIK et al., 1983; NOGUEIRA \& TRUGO, 2003; VITORINO et al., 2001; ZHU et al., 1999). A cafeína, composto relativamente estável durante a torração, embora não participe de nenhuma reação específica, possui importante propriedade farmacológica que é o seu efeito estimulante (BICCHI et al., 1995; MACRAE, 1985). Além do aspecto nutricional, os ácidos clorogênicos são importantes na avaliação sensorial da bebida, sendo precursores importantes dos ácidos fenólicos livres e, por conseguinte, dos compostos fenólicos voláteis que participam da formação do aroma do café torrado (MOREIRA et al., 2000).

Os níveis de cafeína, trigonelina, ácido nicotínico e ácidos clorogênicos em grãos de café têm sido estudados tanto para a discriminação das espécies quanto para avaliação do grau de torração, qualidade e propriedades funcionais do café (BICCHI et al., 1995; CASAL et al., 2000a). A qualidade sensorial da bebida e os possíveis efeitos benéficos à saúde são dependentes tanto da matéria-prima como do ponto de torração utilizado, uma vez que compostos como a trigonelina e os ácidos clorogênicos sofrem intensas degradações durante esse processo. Mediante estas constatações, nesta pesquisa, objetivou-se investigar as alterações na concentração de trigonelina, ácidos clorogênicos e cafeína em cafés de diferentes padrões de bebida, submetidos à torração clara, média e escura.

\section{MATERIAL E MÉTODOS}

As amostras de café (Coffea arabica L.) da safra 2005/2006 foram provenientes de uma empresa de comercialização de café situada no sul de Minas Gerais e classificadas por meio da prova de xícara por provadores profissionais em bebidas mole, dura e rio.

A torração foi efetuada em equipamento Probat, com capacidade para $1 \mathrm{~kg}$, nos graus de torração claro, médio e escuro, sendo o ponto final do processo detectado com o auxílio de discos Probat de acordo com o Programa de Qualidade do Café (PQC) (ABIC, 2007). Em seguida, os grãos crus e torrados foram moídos em moinho refrigerado a $4^{\circ} \mathrm{C}$ (Tecnal), em granulometria fina (70\% de retenção em peneira 20) e armazenados em frascos a $-20^{\circ} \mathrm{C}$, durante 15 dias. As análises foram realizadas no Laboratório de Solos e Nutrição de Plantas da Empresa de Pesquisa Agropecuária de Minas Gerais-EPAMIG, situado em Lavras, MG e no Pólo de Tecnologia em Qualidade do Café da Universidade Federal de Lavras (UFLA).

Para a determinação de cafeína, trigonelina e ácido 5-cafeoilquínico (5-ACQ) foram utilizados procedimentos de extração com água quente (VITORINO et al., 2001). Amostras de café torrado e moído $(0,5 \mathrm{~g})$ foram extraídas com $100 \mathrm{~mL}$ de água destilada em ebulição, agitando-se por 3 minutos em banho-maria a $100^{\circ} \mathrm{C}$. Utilizou-se para as análises cromatográficas um cromatógrafo da marca Schimadzu com coluna em fase reversa $\mathrm{C}-18$. O sistema encontravase acoplado a um detector espectrofotométrico UV/ visível Shimadzu (modelo SPD-10A) conectado por uma interface (CBM-101) a um microcomputador para processamento de dados. As condições de análise 
utilizadas foram fluxo de $1 \mathrm{~mL} \cdot \mathrm{min}^{-1}$; fase móvel: metanol, água e ácido acético (20:80:1); temperatura ambiente; comprimento de onda $272 \mathrm{~nm}$. A concentração dos compostos foi determinada pela relação entre as áreas dos picos de cafeína, trigonelina e ácido clorogênico da amostra e dos respectivos padrões Sigma de concentrações conhecidas.

O delineamento utilizado foi inteiramente casualizado com três repetições sendo os tratamentos dispostos em esquema fatorial $3 \times 4$, constituído pelos tipos de bebida (mole, dura e rio) e pelos pontos de torração (cru, clara, média e escura). Os dados obtidos foram submetidos à análise de variância e comparados pelo Teste de Tukey a $5 \%$ de probabilidade.

\section{RESULTADOS E DISCUSSÃO}

As concentrações de trigonelina, ácido 5cafeoilquínico e cafeína foram calculadas a partir dos cromatogramas obtidos para cada amostra. A figura 1 mostra um dos cromatogramas para o extrato do café cru. Os tempos de retenção correspondentes aos três compostos de interesse foram assim identificados: trigonelina (3,12 minutos), ácido 5-cafeoilquínico (15,70 minutos) e cafeína (16,90 minutos).

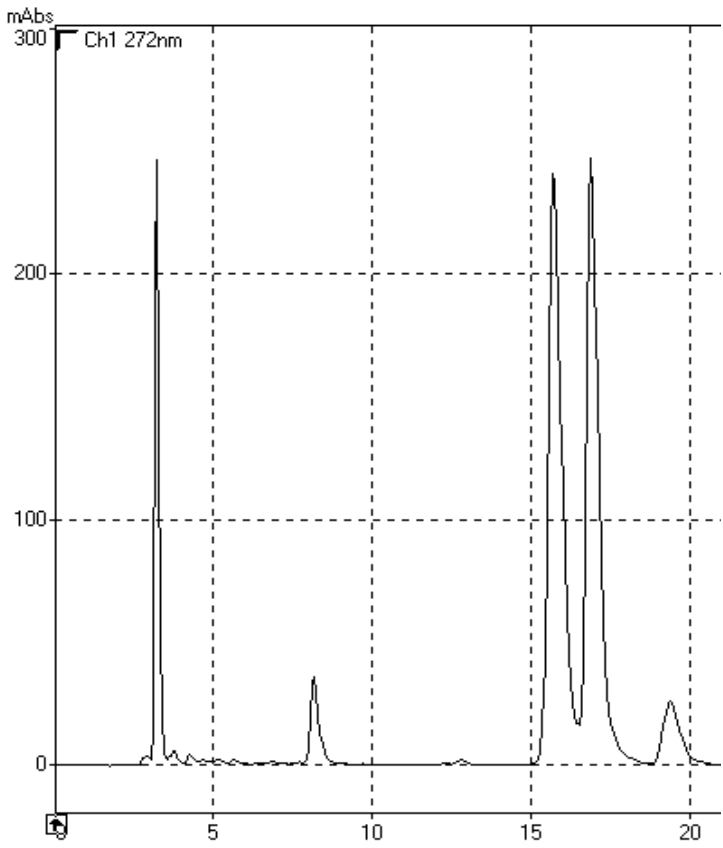

Figura 1 -Cromatograma de uma das amostras de café cru a $272 \mathrm{~nm}$
As concentrações de trigonelina nos diferentes padrões de bebida para os cafés crus e torrados sob diferentes pontos de torração encontram-se na Figura 2. A quantidade de trigonelina extraída no grão cru foi de 1,06; 1,11 e 1,35g.100g ${ }^{1}$ de café para as amostras classificadas como dura, mole e rio, respectivamente. $\mathrm{O}$ valor da trigonelina em grãos crus é variável principalmente em função da espécie, apresentando em geral maiores valores em $C$. arabica quando comparado ao C. canephora Pierre (MARIA et al., 1999).O conhecimento da concentração de trigonelina no grão cru permite estimar o seu potencial de degradação para a formação dos compostos voláteis e do ácido nicotínico (MAZZAFERA, 1991). Para todos os padrões de bebida avaliados neste trabalho, houve uma redução no teor de trigonelina com a intensificação do processo de torração. A bebida rio apresentou a maior degradação de trigonelina, em torno de $85 \%$, considerando o valor do grão cru $\left(1,35\right.$ g. $\left.100 \mathrm{~g}^{-1}\right)$ e da torração escura $(0,20$ g. $\left.100 \mathrm{~g}^{-1}\right)$. Monteiro \& Trugo (2005) relataram valores de 0,2 a $0,5 \mathrm{~g} \cdot 100 \mathrm{~g}^{-1}$ para cafés brasileiros com torração média e extraforte. Em relação aos padrões de bebida não houve diferença entre os teores de trigonelina no grão cru e os grãos submetidos à torração clara. A torração clara, portanto, não contribui para degradação da trigonelina em compostos voláteis e não voláteis. Borges et al. (2004) também observaram degradação da trigonelina em cafés $C$. arabica somente 8 minutos após o início do processo de torração.

As concentrações de ácidos clorogênicos podem variar em função da espécie e variedade do café, da técnica de extração e do método de análise empregado (MOREIRA et al., 2000). Na figura 3, observa-se que para todas as classes de bebida houve redução significativa na concentração do ácido 5-cafeoilquínico quando a torração foi mais acentuada. Portanto, o grau de torração utilizado é um fator importante na composição qualitativa e quantitativa de ácidos clorogênicos (BICCHI et al., 1995). Nos grãos submetidos à torração clara já se observa uma redução nos valores do 5ACQ, o que não foi evidenciado na degradação da trigonelina. Quando foram utilizadas as torrações média e escura as concentrações não diferiram estatisticamente e foram ainda mais baixas quando comparadas à torração clara. Sugere-se que a atividade antioxidante do café diminui à medida que se avança o processo de torração, em razão da perda de componentes fenólicos (CASTILHO et al., 2002; DUARTE et al., 2005). No entanto, a atividade antioxidante do café não se restringe apenas à perda de componentes fenólicos. Outros componentes antioxidantes são formados durante a torração, principalmente resultantes da reação de Maillard (ANESE \& NICOLI, 2003; CASTILHO et al., 2002). Os maiores valores do ácido 5-cafeoilquínico para todos os padrões de bebida foram verificados no grão cru, confirmando o trabalho de Moreira et al. (2000). 


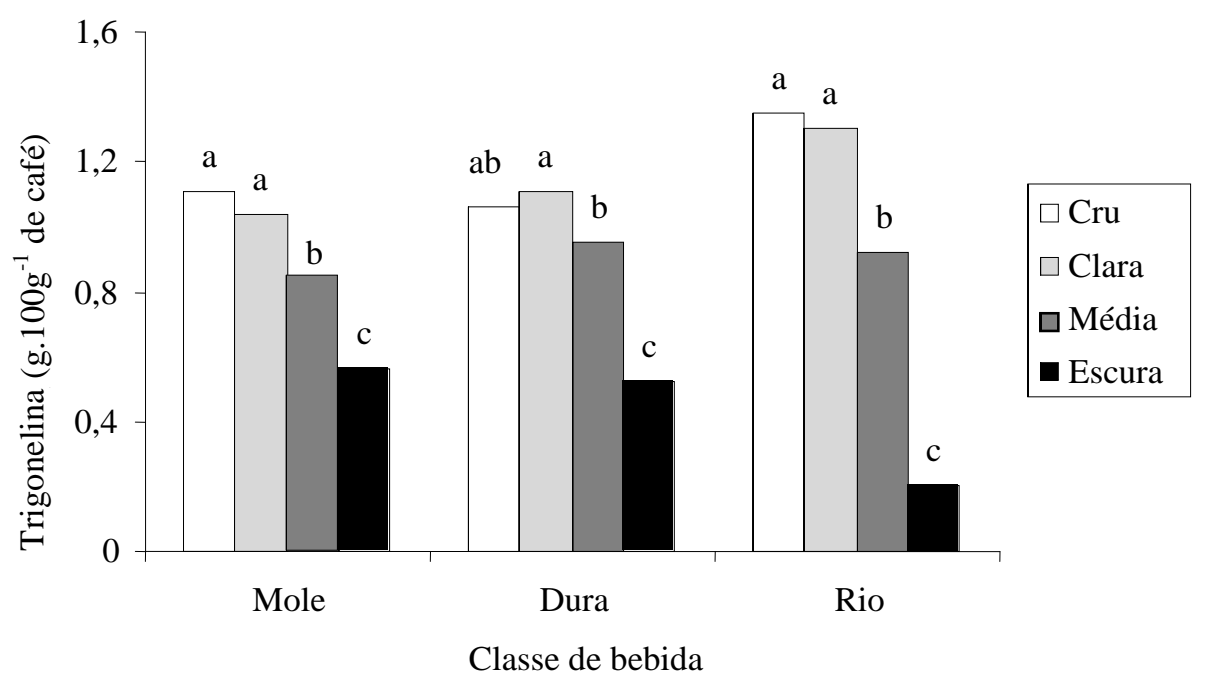

Figura 2 - Teores médios de trigonelina em cafés de diferentes qualidades em função de diferentes pontos de torração. Médias seguidas pela mesma letra não diferem entre si, a 5\% de probabilidade, pelo teste de Tukey. UFLA, Lavras, MG, 2007.

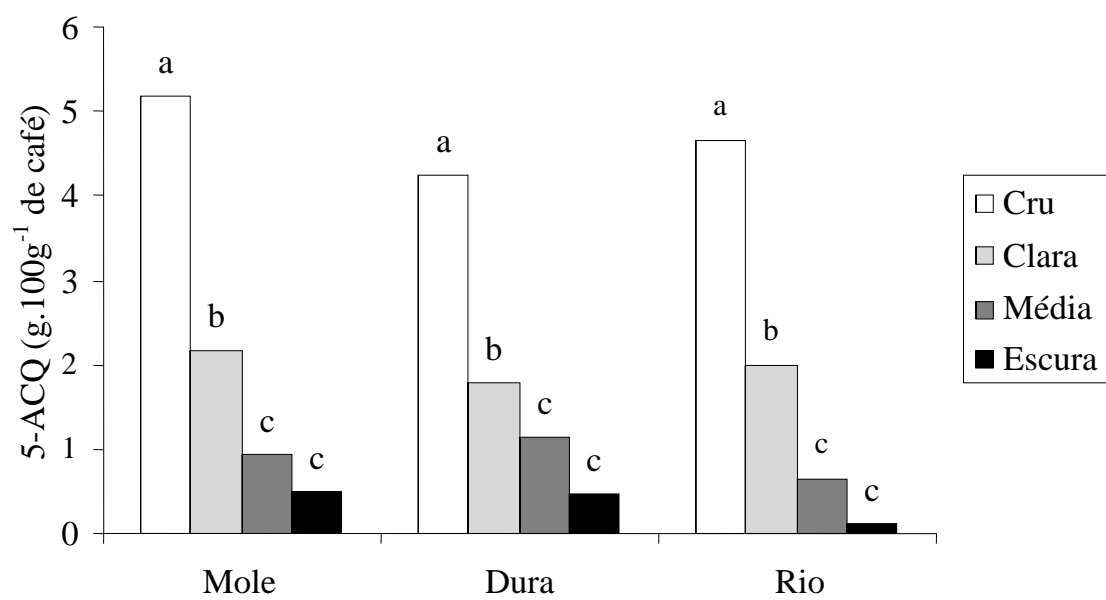

Classe de bebida

Figura 3 - Teores médios de ácido 5-cafeoilquínico (5-ACQ) em cafés de diferentes qualidades em função de diferentes pontos de torração. Médias seguidas pela mesma letra não diferem entre si, a 5\% de probabilidade, pelo teste de Tukey. UFLA, Lavras, MG, 2007.

Os cafés crus e torrados não diferiram entre si quanto à concentração de cafeína, confirmando sua estabilidade térmica durante a torração (Figura 4). O valor encontrado para os grãos crus encontram-se entre os limites relatados na literatura científica de 0,5 a 2 g. $100 \mathrm{~g}^{-1}$ para $C$. arabica (MELLO et al., 1992). A similaridade nos valores obtidos para os grãos crus e torrados indica que independente da qualidade da matéria-prima utilizada, esta substância é mantida nos grãos, principalmente por não participar de reações que ocorrem durante a torração, sendo que quaisquer variações em sua concentração podem ser atribuídas à perda por arraste de vapor e/ou de massa do grão durante o processo (CASAL et al., 2000b; MOREIRA et al., 2000; VITORINO et al., 2001). 


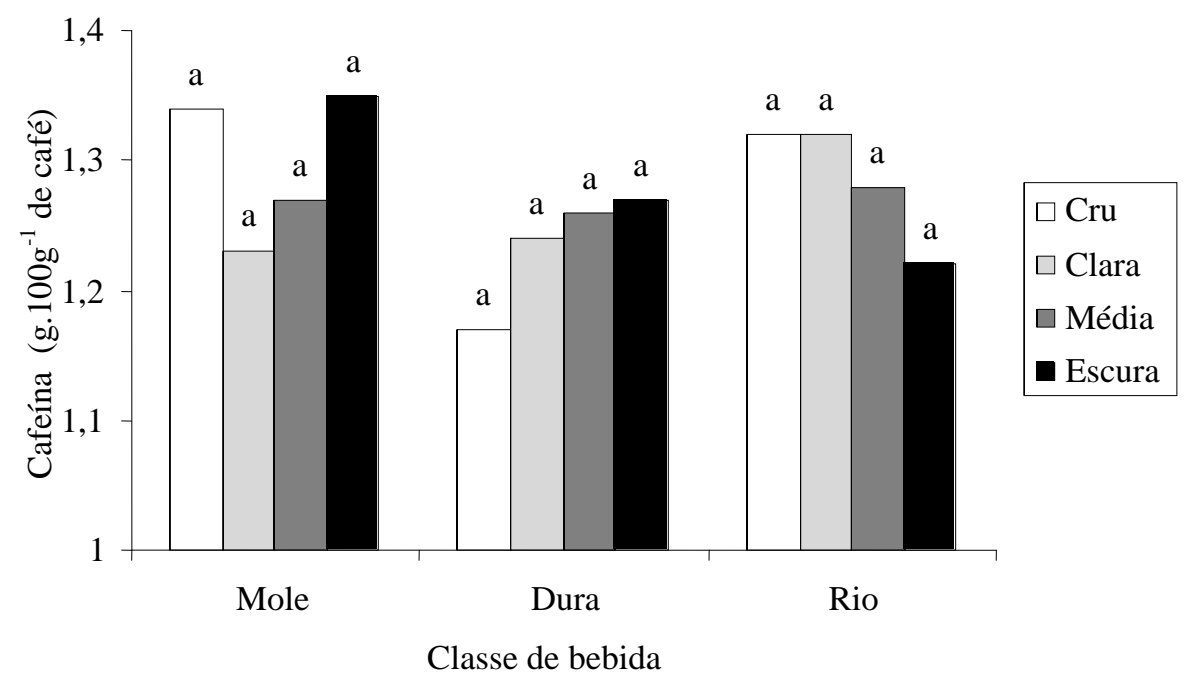

Figura 4 - Teores médios de cafeína em cafés de diferentes qualidades em função de diferentes pontos de torração. Médias seguidas pela mesma letra não diferem entre si, a 5\% de probabilidade, pelo teste de Tukey. UFLA, Lavras, MG, 2007.

\section{CONCLUSÃO}

Para todos os padrões de bebida analisados, o ponto de torração utilizado é um fator importante nas concentrações de trigonelina e ácido 5-cafeoilquínico nos grãos de café. As torrações mais acentuadas promoveram uma maior degradação destes compostos, enquanto que a torração clara promoveu degradação apenas do ácido clorogênico não interferindo nas concentrações da trigonelina. A degradação da cafeína não ocorreu em nenhum ponto de torração.

\section{REFERÊNCIAS BIBLIOGRÁFICAS}

ABIC. Análise da qualidade do café. Disponível em: לhttp://www.abic.com.bri. Acesso em: 10 jan. 2007.

ANESE , M.; NICOLI, M. C. Antioxidant properties of ready-to-drink coffee brews. Journal of Agricultural and Food Chemistry, Washington, v. 51, p. 942-946, 2003.

BICCHI, C. P.; BINELLO, A. E.; PELLEGRINO, G. M.; VANNI, A. C. Characterization of green and roasted coffes through the chlorogenic acid fraction by HPLCUV and principal component analysis. Journal of Agricultural and Food Chemistry, Washington, v. 43, p. 1549-1555, 1995.

BOBBIO, F. O.; BOBBIO, P. A. Introdução à química de alimentos. São Paulo: Varela, 2003. 238 p.
BORGES, M. L. A.; MENDONÇA, J. C. F.; FRANÇA, A. S.; OLIVEIRA, L. S. Perfis de trigonelina, ácido 5cafeoilquínico e cafeína em cafés de diferentes qualidades durante a torração. Revista Brasileira de Armazenamento, Viçosa, v. 8, p. 14-18, 2004. Especial café.

BORÉM, F. B.; NOBRE, G. W.; FERNANDES, S. M.; PEREIRA, R. G. F. A.; OLIVEIRA, P. D. de. Avaliação sensorial do café cereja descascado, armazenado sob atmosfera artificial e convencional. Ciência e Agrotecnologia, v.32, n.6, p. 1724-1729, nov./dez., 2008.

BOUBLIK, J. H.; QUINN, M. J.; CLEMENTS, J. A.; HERINGTON, A. C.; WYNNE, K. N.; FUNNDER, J. W. Coffee contains potent opiate receptor binding activity. Nature, London, v. 301, p. 246-248, 1983.

CASAL, S.; OLIVEIRA, B.; FERREIRA, M. A. HPLC/ diode-array applied to thermal degradation of trigonelline, nicotinic acid and caffeine in coffee. Food Chemistry, London, v. 68, p. 481-485, 2000a.

CASAL, S.; OLIVEIRA, M. B. P. P.; ALVES, M. R.; FERREIRA, M. A. Discriminate analysis of roasted coffee varieties for trigonelline, nicotinic acid and caffeine content. Journal of Agricultural and Food Chemistry, Washington, v. 48, p. 3420-3424, 2000 b. 
CASTILHO, M. D. del; AMES, J. M.; GORDON, M. H. Effect of roasting on the antioxidante activity of coffee brews. Journal of Agricultural and Food Chemistry, Washington, v. 50, p. 3698-3703, 2002.

DUARTE, S. M. S.; ABREU, C. M. P.; MENEZES, H. C.; SANTOS, M. H.; GOUVEA, C. M. C. P. Effect of processing ando roasting on the antioxidant activity of coffee brews. Ciência e Tecnologia de Alimentos, Campinas, v. 25, n. 2, p. 387-383, 2005.

MACRAE, R. Nitrogenous components. In: CLARKE, R.; MACRAE, R. Coffee: chemistry. London: Applied Science, 1985. p. 115-152.

MARIA, C. A. B. de; MOREIRA, R. F. A.; TRUGO, L. C. Compostos voláteis do café torrado.Parte I: compostos heterocíclicos. Química Nova, São Paulo, v. 22, n. 2, p. 209-217, 1999.

MAZZAFERA, P. Trigonelline in coffee.

Phytochemistry, Oxford, v. 30, n. 7, p. 2309-2310, 1991.

MELLO, M. R. P. A.; MINAZZI-RODRIGUES, R. S.; CARVALHO, J. B.; SHIROSE, I. Estudo comparativo de métodos de extração para determinação de cafeína em café. Revista Instituto Adolfo Lutz, São Paulo, v. 52, p. 89-95, 1992.
MONTEIRO, M. C.; TRUGO, L. C. Determinação de compostos bioativos em amostras comerciais de café torrado. Química Nova, São Paulo, v. 28, n. 4, p. 637-641, 2005.

MOREIRA, R. F. A.; TRUGO, L. C.; MARIA, C. A. B. de. Compostos voláteis do café torrado: parte II, compostos alifáticos, alicíclicos e aromáticos. Química Nova, São Paulo, v. 23, n. 2 , p. 195-203, 2000.

NOGUEIRA, M.; TRUGO, L. C. Distribuição de isômeros de ácido clorogênico e teores de cafeína e trigonelina em cafés solúveis brasileiros. Ciência e Tecnologia de Alimentos, Campinas, v. 23, n. 2, p. 296-299, 2003.

PEREIRA, R. G. F. A. Tecnologia e qualidade de café, raízes e tubérculos. Lavras: UFLA/FAEPE, 2003. 54 p.

VITORINO, M. D.; FRANÇA, A. S.; OLIVEIRA, L. S.; BORGES, M. L. A. Metodologias de obtenção de extrato de café visando a dosagem de compostos não voláteis. Revista Brasileira de Armazenamento, Viçosa, v. 3, p. 17-24, 2001. Especial café.

ZHU, K.; CORDEIRO, M. L.; ATIENZA, J.; ROBINSON JUNIOR, W. E.; CHOW, A. S. Irreversible inhibition of human immunodeficiency virus type I integrase by dicaffcoylquinic acids. Journal of Virology, Washington, v. 73, p. 3309-3316, 1999. 